\title{
A Cluster Analysis of Physical Activity and Sedentary Behavior Patterns in Middle School Girls
}

\author{
Jennifer L. Trilk, Ph.D. ${ }^{a}$, Russell R. Pate, Ph.D. ${ }^{a}$, Karin A. Pfeiffer, Ph.D. ${ }^{b}$, Marsha Dowda, \\ Dr.P.H. ${ }^{a}$, Cheryl L. Addy, Ph.D. ${ }^{a}$, Kurt M. Ribisl, Ph.D. ${ }^{c}$, Dianne Neumark-Sztainer, Ph.D., \\ M.P.H., R.D. ${ }^{d}$, and Leslie A. Lytle, Ph.D. ${ }^{e}$ \\ aDepartment of Exercise Science, Arnold School of Public Health, University of South Carolina, \\ Columbia, South Carolina \\ bDepartment of Kinesiology, College of Education, Michigan State University, East Lansing, \\ Michigan \\ 'Department of Health Behavior and Health Education, School of Global Public Health, University \\ of North Carolina at Chapel Hill, Chapel Hill, North Carolina \\ dDivision of Epidemiology and Community Health, School of Public Health, University of \\ Minnesota \\ eDivision of Epidemiology and Community Health, School of Public Health, University of \\ Minnesota, Minneapolis, Minnesota
}

\section{Abstract}

PURPOSES-To identify similar patterns of physical activity (PA) and sedentary behavior in $6^{\text {th }}$ grade girls using cluster analysis; to determine which clusters of girls were associated with greater daily minutes of objectively-measured PA; and to examine whether girls in these clusters experienced change in PA from $6^{\text {th }}$ to $8^{\text {th }}$ grade.

METHODS-An adventitious cohort of girls (N=957) from the Trial of Activity for Adolescent Girls (TAAG) were measured at $6^{\text {th }}$ and $8^{\text {th }}$ grade. Activities were identified using the 3 -day physical activity recall (3DPAR) and a self-report survey and used to create clusters of $6^{\text {th }}$ grade girls who had similar PA/sedentary behaviors. Accelerometry was used to assess PA in $6^{\text {th }}$ and $8^{\text {th }}$ grade. Data analysis consisted of FASTCLUS and mixed model repeated measures analyses in SAS.

RESULTS-Cluster analysis yielded 6 clusters (C1: Educational sedentary, C2: Sports and play, C3: Organized sports teams/classes/lessons in past year, C4: Active transport and chores, C5: Electronic media; C6: Sleep). Sixth-grade girls in C2 and C3 had greater average daily minutes of moderate-to-vigorous physical activity (MVPA), MET-weighted MVPA, and vigorous physical activity (VPA) compared to other clusters $(\mathrm{p}<0.05)$. In $8^{\text {th }}$ grade, sedentary time increased and

\footnotetext{
(C) 2011 Society for Adolescent Medicine. Published by Elsevier Inc. All rights reserved.

Contact Information: Jennifer L. Trilk, Department of Exercise Science, Arnold School of Public Health, 921 Assembly St., Suite 212, University of South Carolina, Columbia, SC 29208, Phone: 803-777-0280, Fax: 803-777-2504, trilk@ mailbox.sc.edu.

Implications and Contribution

Adolescent girls exhibit complex behavior patterns that include both physical and sedentary activities. These patterns must be considered when encouraging girls to be more physically active. Specifically, participating in organized sports, classes or lessons may increase adolescent girls' physical activity levels and help sustain their physical activity levels over time.

Publisher's Disclaimer: This is a PDF file of an unedited manuscript that has been accepted for publication. As a service to our customers we are providing this early version of the manuscript. The manuscript will undergo copyediting, typesetting, and review of the resulting proof before it is published in its final citable form. Please note that during the production process errors may be discovered which could affect the content, and all legal disclaimers that apply to the journal pertain.
} 
physical activity declined among girls in all clusters $(\mathrm{p}<0.05)$. Girls in $\mathrm{C} 2$ had the greatest decline in PA, whereas girls' PA in $\mathrm{C} 3$ declined less.

CONCLUSION-Encouraging participation in organized sports teams/class/lessons in middle school girls may promote greater MVPA and VPA than other activities, and may help to better sustain PA levels over time.

\section{Keywords}

Accelerometry; MVPA; Sports; Adolescents; 3DPAR

\section{Introduction}

Physical activity in youth is central to healthy growth and maturation [1, 2]; however, only $8 \%$ of $12-15$ year olds meet physical activity recommendations of attaining $\geq 60$ minutes per day of moderate-to-vigorous physical activity (MVPA) [3]. In addition, average daily minutes of MVPA has been shown to decline $48 \%$ in boys and 54\% in girls from age 9-15 [4], with a decrease of up to $83 \%$ in girls by age $19[3,5]$. Because adolescence is a time where life long-behaviors are established [6], public health efforts are ongoing to promote physical activity participation, especially in girls $[3,7]$. Identifying patterns of physical activity behavior in adolescent girls may help improve interventions designed to help girls become and stay active into adulthood.

Cluster analysis is a useful statistical technique that can allocate individuals into groups based on the characteristics they have in common [8, 9]. Using cluster analysis, Nelson et al. [10] found that $7^{\text {th }}$ to $12^{\text {th }}$ graders who reported high levels of skating/video game participation, sports participation with parents, and school team/individual sports/academic clubs participation were more likely to meet national physical activity guidelines compared to adolescents who reported high television/video and video gaming. The decline of physical activity levels into adulthood also varied by cluster but was most dramatic in skaters/video gamers. Self-report was used to determine physical activity levels; therefore, the outcome may have been affected by common biases such as social desirability, problems with recall, and over-reporting of time spent in daily physical activity.

Accelerometry provides a more accurate and reliable measure of physical activity levels than self-report [11]. Therefore, a more robust association between physical activity/ sedentary behaviors and physical activity levels may be achieved by using accelerometry to measure physical activity levels and a questionnaire to provide context of physical activity/ sedentary behaviors. Patnode et al. [12] categorized $6^{\text {th }}-11^{\text {th }}$ graders into 3 classes:

"Active," "Sedentary," and "Low Media/Functional Activity (girls)" or "Moderate Activity (boys)," and found differences in gender, age, and body fatness across classes. While they examined adolescents at one time point, using accelerometry incorporated with cluster analysis may help to identify types of physical activity in adolescents that are associated with sustainable, healthful physical activity levels over time.

The purposes of this study were: 1) to identify similar patterns of physical activity and sedentary behaviors in $6^{\text {th }}$ grade girls using cluster analysis, 2 ) to determine which clusters of girls were associated with greater daily minutes of objectively-measured physical activity, and 3) to examine whether girls in these clusters experienced any change in physical activity from $6^{\text {th }}$ to $8^{\text {th }}$ grade. The study used accelerometry to measure physical activity levels and a self-report instrument to identify the context of physical activity/sedentary behaviors. 


\section{METHODS}

\section{Study design}

This research involved an analysis of data from an adventitious cohort of girls $(\mathrm{N}=1285)$ who were measured in both $6^{\text {th }}$ and $8^{\text {th }}$ grades as part of the Trial of Activity for Adolescent Girls (TAAG). TAAG was a multi-center, effectiveness study of a physical activity intervention in middle school girls $[13,14]$. The design of the current study included a crosssectional component (girls measured at $6^{\text {th }}$ grade) to identify clusters of common activities and their associations with physical activity levels, and a prospective longitudinal component (girls measured at $6^{\text {th }}$ and $8^{\text {th }}$ grade) to determine change in physical activity over time. The original TAAG intervention did not result in statistically significant differences in physical activity levels between control and intervention groups at $8^{\text {th }}$ grade [13]; therefore, all girls were combined for this study. Of the 1285 girls in the adventitious cohort, 957 (74.5\%) of girls completed 6 consecutive days of accelerometry measurement as well as the 3-Day Physical Activity Recall (3DPAR) [15] and a survey to obtain types of physical activity performed. Therefore, data from 957 girls were used to create the clusters and were analyzed to determine which clusters were associated with greater daily minutes of physical activity and change in physical activity behavior from $6^{\text {th }}$ to $8^{\text {th }}$ grade. TAAG was conducted at 36 sites in 6 states throughout the U.S. with study coordination provided by the University of North Carolina at Chapel Hill. The study was approved by the participating universities' institutional review boards.

\section{Participants}

Girls provided demographic information, including age, race (white, African American, Hispanic, or other if multiracial, Native Hawaiian, or Pacific Islander), and parent education. Girls' age was calculated by subtracting the girls' date of birth from the date that the consent form was completed. Standing height and weight were measured using a standardized protocol [13], and Body Mass Index (BMI) was calculated as weight(kilograms)/ height(meters) ${ }^{2}$.

\section{Objectively-measured physical activity}

Total daily physical activity was measured with the ActiGraph accelerometer (ActiGraph model 7164; Pensacola, FL) [13]. The accelerometers were initialized to save data in 30second intervals (epochs) [16, 17]. Participants were instructed to wear the accelerometers on an elastic belt on the right hip (anterior to the iliac crest) during all waking hours to capture six consecutive days of wear, which included both weekend days. For analyses, data were reduced and missing data were imputed according to previously-published methods $[17,18]$. On average, approximately 12 hours of data per girl were imputed across the 6 days of data collection. The count threshold used for MVPA (4.6 METs) was 1500 counts/30 seconds as developed by Trueth et al. [17] for the main trial data from TAAG, since it had a good model fit $\left(\mathrm{R}^{2}=0.84\right)$ for $8^{\text {th }}$ grade girls. Daily MET-weighted minutes of MVPA were calculated by summing METs (metabolic equivalent of a physical activity) for MVPA over the entire day. The count thresholds used for sedentary, light physical activity (LPA), and vigorous physical activity (VPA, 6.5 METs) were $<50$ counts/30 seconds, 50-1,499 counts/ 30 seconds, and 2600 counts/30 seconds, respectively [17].

\section{Self-reported physical activity}

At $6^{\text {th }}$ grade (baseline), girls completed the 3DPAR [15] to identify the types of physical activity in which they engaged. A list of 71 activities categorized into eating, after school/ spare time/hobbies, sleep/bathing, school, transportation, work, and physical activities was provided. Girls recalled their predominant activity in 30-min time blocks (6 a.m. to 12 
midnight) every day for the preceding three days, and each activity reported was averaged across the 3 days of recall for each girl. Girls also completed a survey regarding participation in sports teams (in school and outside school) and any physical activity classes/ lessons taken outside of school during the past year. The maximum possible number of organized sports teams/classes/lessons in which girls could have participated was fortyeight.

The 3DPAR and survey data were used to create clusters. The activities most often reported on the 3DPAR $[6,19]$ were summed and labeled within researcher-identified activity types (Educational sedentary, Sports and play, Active transportation and chores, Electronic media, and Sleep). Responses from the survey were used to construct counts for the number of organized school sports teams, community sports teams, classes or lessons in which girls participated within the past year. Girls were classified into clusters either based upon the most frequently reported activities averaged over 3 days or the number of organized sports/ teams/classes they participated in within the past year. Data were normalized (z-scores) prior to cluster analysis to be able to compare activity contexts.

\section{Statistical analyses}

To identify similar patterns of physical activity and sedentary behaviors in $6^{\text {th }}$ grade girls, cluster analysis (SAS FASTCLUS, Research Triangle Institute, Research Triangle Park NC, 2004) was performed using Z-scores from the six summary variables constructed from the self-reports. The cluster analysis procedure identified individuals based on similar patterns and placed them into clusters based on Euclidean distances between observations. Multiple iterations were conducted to identify the optimal number of clusters that produced the greatest heterogeneity between clusters compared to within clusters $\left(\mathrm{r}^{2}\right)$. For example, a high $\mathrm{r}^{2}$ indicated that the girls placed in a given cluster differed more from girls in other clusters than from those in that same cluster [20]. In addition, cluster robustness was performed (cubic clustering criterion). A cubic clustering criterion of greater than 2 indicates that the clustering outcome is robust [21].

Secondly, to determine which clusters of girls were associated with greater daily minutes of physical activity in $6^{\text {th }}$ and $8^{\text {th }}$ grade, the average number of daily minutes of sedentary, LPA, MVPA, and VPA were calculated and compared across clusters using analysis of variance (ANOVA, SAS version 9.2). Data for VPA were highly skewed and therefore were square root-transformed to normalize the data for analysis. Finally, to examine whether girls in these clusters experienced any change in physical activity from $6^{\text {th }}$ to $8^{\text {th }}$ grade, a mixed model repeated measures ANOVA was used to compare minutes/day of the physical activity variables across clusters in the $6^{\text {th }}$ and $8^{\text {th }}$ grade, adjusting for schools from the original study design. All models controlled for age, BMI, race, and free/reduced lunch. Girls were nested within schools, and schools were nested within the study site and treated as a random variable. Statistical significance was set at an a level of 0.05 .

\section{Results \\ Cluster characteristics}

The optimal number of clusters ( 6 clusters) that emerged from the $6^{\text {th }}$ grade data yielded an $\mathrm{r}^{2}=0.43$, and a cubic clustering criterion $=12.6$, indicating that the clustering outcome was robust. Cluster size ranged from 75 to 253 girls (total $\mathrm{N}=957$, Table 1). The most prevalent activity group in each cluster paralleled the activity groupings; therefore, each girl was placed via cluster analysis into one of the 6 clusters: C1: Educational sedentary (i.e., homework, read, music lesson/playing instrument, listen to music); C2: Sports and play (i.e., basketball, running, gymnastics, volleyball, track, walk for exercise, softball, dance, and 
playground games); C3: Organized sports teams/classes/lessons in past year (i.e., participated in school sports teams, community sports teams, classes or lessons within the past year); C4: Active transportation and chores (i.e., travel by walking, travel by bike, playing with younger children, chores); C5: Electronic media (i.e., watching TV or a movie, talking on the phone, playing music, and play video games/surfing internet); and C6: Sleep (i.e., between 6am and 12am).

The girls' other activities also were examined within each cluster, and some of the clusters had notable patterns (Table 1). Girls who had high participation in Electronic media had low participation in Educational sedentary and Sports and play. Conversely, girls who had high participation in Educational sedentary had low participation in other activities, but particularly had the lowest participation in Electronic media compared to other girls. Girls who had high participation in Sleep from 6am-12 midnight ( $\geq 2,30$-minute blocks more than other girls) had low participation in Organized sports teams/classes/lessons in past year.

\section{Participant characteristics}

Mean $( \pm \mathrm{SD})$ age and BMI of the girls at $6^{\text {th }}$ grade were $11.9 \pm 0.4$ years and $20.6 \pm 4.7 \mathrm{~kg}$ / $\mathrm{m}^{2}$, respectively. Prevalence of overweight and obesity at $6^{\text {th }}$ grade was $17.5 \%\left(85^{\text {th }}\right.$ percentile of BMI-CDC) and $15.7 \%$ (95 ${ }^{\text {th }}$ percentile of BMI-CDC), respectively [22]. Neither age nor BMI were significantly different across clusters. Of the cohort of 957 girls, 52\% were white, $19.3 \%$ African American, $18.8 \%$ Hispanic, and 9.8\% other. Forty-nine percent of girls reported obtaining school free/reduced lunch and $13.6 \%$ did not know. Race distribution was significantly different across clusters ( $\mathrm{p}<0.001$, Table 2). African American girls mostly participated in C5: Electronic media and least in C1: Educational sedentary. White girls mostly participated in C1: Educational sedentary and least in C3: Organized sports teams/classes/lessons in past year. Hispanic girls also mostly participated in C5: Electronic media, but least in C2: Sports and play and C4: Active transportation and chores. There was a relatively equal percent of race/ethnicity participation in C6: Sleep (22-29\%). Additionally, free/reduced lunch was significantly different across clusters $(\mathrm{p}<0.001)$. The greatest percentage of girls who received free/reduced lunch was in C5: Electronic media.

\section{Physical activity levels by cluster}

In $6^{\text {th }}$ grade, girls in C2: Sports and play had the greatest average daily minutes of MVPA and MET-weighted MVPA, followed by girls in C3: Organized sports teams/classes/lessons in past year, and these were statistically greater than for girls in other clusters $(\mathrm{p}<0.05$, Table $3)$. No statistical difference was found between $\mathrm{C} 2$ and $\mathrm{C} 3$ for MVPA $(P=0.20)$ and METweighted MVPA $(P=0.20)$. Average daily minutes of VPA were greater in girls in C2: Sports and play as compared to girls in C1: Educational sedentary ( $<<0.001), \mathrm{C} 4$ : Active transportation and chores $(\mathrm{p}=0.008), \mathrm{C} 5$ : Electronic media $(\mathrm{p}<0.001)$, and C6: Sleep $(\mathrm{p}=0.04)$. Average daily minutes of VPA for girls in C3: Organized sports teams/classes/ lessons in past year were also greater than girls in $\mathrm{C} 1$ : Educational sedentary $(\mathrm{p}=0.001)$ and C5: Electronic media $(\mathrm{p}=0.01$ ). Sixth-grade girls in C2: Sports and play and C3: Organized sports teams/classes/lessons in past year had less sedentary minutes and more LPA than girls in C1: Educational sedentary ( $\mathrm{p}<0.05)$.

As girls transitioned to $8^{\text {th }}$ grade, minutes of sedentary time increased and LPA declined among girls across clusters $(\mathrm{p}<0.05)$. There was no cluster by time interaction for average daily minutes of sedentary time or LPA. A statistically significant cluster by time interaction existed across clusters for average daily minutes of MVPA, MET-weighted MVPA, and VPA ( $\mathrm{p} \unlhd .001$ for all variables), which is presented in Figure 1. Girls in C2: Sports and play had the greatest decline in daily minutes of MVPA (23.8\%, Fig. 1a), MET-weighted MVPA (25.4\%, Fig. 1b), and VPA (16\%, Fig. 1c); followed by girls in C3: Organized sports teams/ 
classes/lessons in past year $(12.1 \%, 13.9 \%$, and $8.7 \%$, respectively). Girls in C4: Active transportation and chores remained the cluster in which girls sustained the highest minutes/ day MVPA and MET-weighted MVPA overall.

\section{Discussion}

\section{Physical activity behavior}

This study was the first to examine accelerometry-measured physical activity with leisuretime behavior via cluster analysis to determine which physical activity and sedentary behavior patterns of $6^{\text {th }}$ and $8^{\text {th }}$ grade girls are associated with greater average daily minutes of physical activity. In addition, this research examined how clusters of behavioral patterns were associated with change in physical activity between $6^{\text {th }}$ and $8^{\text {th }}$ grade. The analysis successfully identified clusters of girls based on their similar physical activity/sedentary behavior patterns and demonstrated meaningful variability among clusters, physical activity levels within the clusters, and the decline in physical activity observed in clusters over time. A key finding was that sixth-grade girls who participated in C2: Sports and play, followed by girls who participated in C3: Organized sports teams/classes/lessons in past year, had the greatest average daily minutes of MVPA, MET-weighted MVPA and VPA compared to girls who participated in other activities. However, girls in $\mathrm{C} 2$ had the greatest decline in average daily minutes of all three physical activity variables by $8^{\text {th }}$ grade, while physical activity levels of girls in $\mathrm{C} 3$ were better sustained over time. These findings are similar to others who have found low levels of physical activity as well as precipitous declines of physical activity over time for adolescent girls [3-5, 23]. Conversely, girls involved in organized sports, classes or lessons may provide each other social support through social integration, encouragement, or companionship when participating in physical activities together [24, 25], or they may naturally develop positive, routine, and consistent physical activity behaviors within an organized group. Indeed, Pate et al. [26] found that $8^{\text {th }}$ grade girls spend more time participating in team sports than $6^{\text {th }}$ grade girls, a pattern that is consistent with structured practice sessions. Subsequently, girls who participate in organized physical activities are at less risk of decreasing physical activity levels through $8^{\text {th }}$ grade. Therefore, sixth grade girls should be encouraged to participate in organized activities that are consistent with higher levels of moderate to vigorous physical activity and are likely to track through adolescence.

Girls who participated in C4: Active transportation and chores had the third-highest average daily minutes of physical activity, but also experienced significantly less of a decline than $\mathrm{C} 2$ and $\mathrm{C} 3$ from $6^{\text {th }}$ to $8^{\text {th }}$ grade. It is possible that these girls obtained and sustained greater physical activity levels because they are required to perform active travel or duties related to the home environment, such as to baby sit younger siblings. Because the nature of the physical activity is more occupational and less recreational, it is unlikely that the physical activity obtained by performing these activities would diminish over time, explaining less of a decrease of physical activity levels into $8^{\text {th }}$ grade than girls in other clusters. In women, employment, household, and other chores are a significant but largely overlooked component of total weekly energy expenditure [27, 28]. These occupational activities may be equally as important for providing physical activity in some adolescent girls.

\section{Sedentary behavior}

Sixth-grade girls in C2: Sports and play and C3: Organized sports teams/classes/lessons in past year also had the lowest average minutes of sedentary behavior compared to the other clusters, suggesting that girls may have substituted leisure-time sedentary behavior with the activities identified in these clusters. Indeed, girls who had excessive participation in Sleep (C6) between 6am and 12am-midnight had the lowest participation in C3, and had very low 
participation in $\mathrm{C} 2$. Some studies propose that sedentary behavior does not limit time for physical activity [29-31]; however, others suggest that involvement in sedentary behavior limits the time available for participation in health-enhancing physical activity [9]. Owen et al. [32] suggest that sedentary behavior sometimes competes with, and sometimes coexists with, physical activity. Nevertheless, prolonged sedentary behavior increases risk of obesity, metabolic syndrome, type 2 diabetes and cardiovascular disease by counteracting the healthprotective effects of physical activity [33].

Regardless of the cluster, the number of sedentary minutes per day increased $\sim 11 \%$ from $6^{\text {th }}$ to 8th grade across all clusters. Girls who predominantly participated in C1: Educational sedentary in $6^{\text {th }}$ grade had the greatest average sedentary minutes per day in $8^{\text {th }}$ grade, followed closely by girls with the greatest participation in C5: Electronic media. Other studies also have found that sedentary behavior tracks from childhood through adolescence and into early adulthood [34-36]. Girls who reported more sleep compared to other girls ( $\geq 2,30$-minute blocks) between 6am and 12am (C6) also reduced their physical activity and increased their sedentary behavior in $8^{\text {th }}$ grade. Although sleep is a physiological necessity in a developing adolescent's 24-hour day, any excessive sleep accrued may compete with time that could be allocated for leisure activities that are more action oriented [37]. Overall, interventions that encourage girls to get involved in Sports and play (C2) and Organized sports teams/classes/lessons in past year (C3) may reduce the amount of time spent in sedentary activities and increase physical activity in adolescent girls.

\section{Girls' behavior patterns within clusters}

Some notable patterns within the girls' physical activity/sedentary behaviors were identified. First, $6^{\text {th }}$ grade girls who had the highest participation in Electronic media had low participation in Educational sedentary, and very low participation in Sports and play. The Future of Children 2004 Data indicates that adolescents ages 11-14 use various electronic media on average 6 hours/day [38]. Flammer and Alsaker [37] identified negative associations between electronic media use and completing school homework, reading books, engaging in sports, and performing outdoor physical activities, and also found that adolescents who used electronic media for extended hours spent more time sleeping than other adolescents. It is clear that interventions are needed to help adolescents who spend excessive amounts of time engaging in recreational electronic media use to decrease these sedentary behaviors and subsequently improve their educational and physical activity behaviors.

\section{Strengths and limitations}

Strengths of this study included using accelerometry to obtain a more robust association between physical activity/sedentary behaviors and physical activity levels in adolescent girls; remeasuring girls at $8^{\text {th }}$ grade to examine the sustainability of physical activity through middle school; and including a diverse sample of girls from 6 states to increase generalizability for race, SES, and other characteristics. A limitation to using accelerometry is the inability to capture certain activities (e.g. swimming, walking up stairs, bike riding); however, the activities used to create the clusters were representative of the most common activities performed by a nation-wide representative cohort of $6^{\text {th }}$ grade girls [19]. A potential bias of the accelerometer methodology may have been the cutpoints chosen for the physical activity variables. However, these cutpoints were defined in a preliminary study using middle-school girls from the catchment areas of three TAAG field centers where accelerometer counts were calibrated against measured energy expenditure $\left(\mathrm{V}_{2}\right)$, and cutpoints were estimated from a regression equation that had a good model fit $\left(\mathrm{R}^{2}=0.84\right)$ [17]. Finally, interpretation of this information beyond girls in middle school should be made with caution. 


\section{Conclusions and future directions}

Since physical activity/sedentary behavior patterns are complex and not independent, future policy and environmental interventions aiming to increase adolescent girls' physical activity should be directed towards altering patterns of behavior rather than concentrating on altering a single type of physical activity to increase chance of success. Specifically, encouraging participation in organized sports teams/class/lessons may promote more participation in MVPA and VPA in adolescent girls than other activities and may help to better sustain physical activity levels over time. Decreasing girls' time spent participating in electronic media activities and excessive sleep may allocate more time for physical activity during leisure time. Further studies should examine physical activity/sedentary behavior patterns with objectively-measured physical activity in adolescent boys, as well as compare these associations between genders.

\section{References}

1. Strong WB, Malina RM, Blimkie CJ, et al. Evidence based physical activity for school-age youth. J Pediatr. 2005; 146:732-7. [PubMed: 15973308]

2. Sothern MS, Loftin M, Suskind RM, et al. The health benefits of physical activity in children and adolescents: implications for chronic disease prevention. Eur J Pediatr. 1999; 158:271-4. [PubMed: 10206121]

3. Troiano RP, Berrigan D, Dodd KW, et al. Physical activity in the United States measured by accelerometer. Med Sci Sports Exerc. 2008; 40:181-8. [PubMed: 18091006]

4. Riddoch CJ, Bo AL, Wedderkopp N, et al. Physical activity levels and patterns of 9- and 15-yr-old European children. Med Sci Sports Exerc. 2004; 36:86-92. [PubMed: 14707773]

5. Kimm SY, Glynn NW, Kriska AM, et al. Decline in physical activity in black girls and white girls during adolescence. N Engl J Med. 2002; 347:709-15. [PubMed: 12213941]

6. Kuo J, Schmitz KH, Evenson KR, et al. Physical and social contexts of physical activities among adolescent girls. J Phys Act Health. 2009; 6:144-52. [PubMed: 19420391]

7. Pate RR, Dowda M, O'Neill JR, et al. Change in physical activity participation among adolescent girls from 8th to 12th grade. J Phys Act Health. 2007; 4:3-16. [PubMed: 17489003]

8. Nelson MC, Gordon-Larsen P, Adair LS, et al. Adolescent physical activity and sedentary behavior: patterning and long-term maintenance. Am J Prev Med. 2005; 28:259-66. [PubMed: 15766613]

9. Marshall SJ, Biddle SJH, Sallis JF, et al. Clustering of sedentary behaviors and physical activity among youth: A cross-national study. Pediatr Exerc Sci. 2011; 14:401-17.

10. Nelson MC, Gordon-Larsen P, Adair LS, et al. Adolescent physical activity and sedentary behavior: patterning and long-term maintenance. Am J Prev Med. 2005; 28:259-66. [PubMed: 15766613]

11. Sirard J, Pate RR. Physical activity assessment in children and adolescents. Sports Med. 2001; 31:439-54. [PubMed: 11394563]

12. Patnode CD, Lytle LA, Erickson DJ, et al. Physical activity and sedentary activity patterns among children and adolescents: a latent class analysis approach. J Phys Act Health. 2011; 8:457-67. [PubMed: 21597117]

13. Webber LS, Catellier DJ, Lytle LA, et al. Promoting physical activity in middle-school girls: Trial of Activity for Adolescent Girls. Am J Prev Med. 2008; 34:173-84. [PubMed: 18312804]

14. Stevens J, Murray DM, Catellier DJ, et al. Design of the Trial of Activity in Adolescent Girls (TAAG). Contemp Clin Trials. 2005; 26:223-33. [PubMed: 15837442]

15. Pate RR, Ross R, Dowda M, et al. Validation of a three-day physical activity recall instrument in female youth. Pediatr Exerc Sci. 2003; 15:257-65.

16. Schmitz KH, Treuth M, Hannan P, et al. Predicting energy expenditure from accelerometry counts in adolescent girls. Med Sci Sports Exerc. 2005; 37:155-61. [PubMed: 15632682]

17. Treuth MS, Schmitz K, Catellier DJ, et al. Defining accelerometer thresholds for activity intensities in adolescent girls. Med Sci Sports Exerc. 2004; 36:1259-66. [PubMed: 15235335] 
18. Catellier DJ, Hannan PJ, Murray DM, et al. Imputation of missing data when measuring physical activity by accelerometry. Med Sci Sports Exerc. 2005; 37:S555-S562. [PubMed: 16294118]

19. Pate RR, Sallis JF, Ward DS, et al. Age-related changes in types and contexts of physical activity in middle school girls. Am J Prev Med. 2010; 39:433-9. [PubMed: 20965380]

20. Nelson MC, Gordon-Larsen P, Adair LS, et al. Adolescent physical activity and sedentary behavior: patterning and long-term maintenance. Am J Prev Med. 2005; 28:259-66. [PubMed: 15766613]

21. SAS Publishing. SAS (R) Technical Report A-108, Cubic Clustering Criterion. 1. Cary: SAS Institute Inc; 1983.

22. Ogden CL, Kuczmarski RJ, Flegal KM, et al. Centers for Disease Control and Prevention 2000 growth charts for the United States: Improvements to the 1977 National Center for Health Statistics version. Pediatrics. 2002; 109:45-60. [PubMed: 11773541]

23. Kimm SY, Glynn NW, Kriska AM, et al. Longitudinal changes in physical activity in a biracial cohort during adolescence. Med Sci Sports Exerc. 2000; 32:1445-54. [PubMed: 10949011]

24. Duncan SC, Duncan TE, Strycker LA. Sources and types of social support in youth physical activity. Health Psychol. 2005; 24:3-10. [PubMed: 15631557]

25. Dowda M, McKenzie TL, Cohen DA, et al. Commercial venues as supports for physical activity in adolescent girls. Prev Med. 2007; 45:163-8. [PubMed: 17673281]

26. Pate RR, Stevens J, Webber LS, et al. Age-related change in physical activity in adolescent girls. J Adolesc Health. 2009; 44:275-82. [PubMed: 19237114]

27. Dowda M, Pfeiffer KA, Dishman RK, et al. Associations among physical activity, health indicators, and employment in 12th grade girls. J Womens Health. 2007; 16:1331-9.

28. Blair SN, Kohl HW, Barlow CE. Physical activity, physical fitness, and all-cause mortality in women: Do women need to be active? J Am Coll Nutr. 1993; 12:368-71. [PubMed: 8409097]

29. Katzmarzyk PT, Malina RM, Song TM, et al. Television viewing, physical activity, and healthrelated fitness of youth in the Quebec Family Study. J Adolesc Health. 1998; 23:318-25. [PubMed: 9814394]

30. Nelson MC, Gordon-Larsen P, Adair LS, et al. Adolescent physical activity and sedentary behavior: patterning and long-term maintenance. Am J Prev Med. 2005; 28:259-66. [PubMed: 15766613]

31. Nelson MC, Gordon-Larsen P. Physical activity and sedentary behavior patterns are associated with selected adolescent health risk behaviors. Pediatrics. 2006; 117:1281-90. [PubMed: 16585325]

32. Owen N, Leslie E, Salmon J, et al. Environmental determinants of physical activity and sedentary behavior. Exerc Sport Sci Rev. 2000; 28:153-8. [PubMed: 11064848]

33. Hamilton MT, Hamilton DG, Zderic TW. Role of low energy expenditure and sitting in obesity, metabolic syndrome, type 2 diabetes, and cardiovascular disease. Diabetes. 2007; 56:2655-67. [PubMed: 17827399]

34. Nelson MC, Gordon-Larsen P, Adair LS, et al. Adolescent physical activity and sedentary behavior: patterning and long-term maintenance. Am J Prev Med. 2005; 28:259-66. [PubMed: 15766613]

35. Pate RR, Trost SG, Dowda M, et al. Tracking of physical activity, physical inactivity, and healthrelated physical fitness in rural youth. Pediatr Exerc Sci. 1999; 11:364-76.

36. Janz KF, Burns TL, Levy SM. Tracking of activity and sedentary behaviors in childhood: The Iowa Bone Development Study. Am J Prev Med. 2005; 29:171-8. [PubMed: 16168865]

37. Flammer A, Alsaker FD. Adolescent electronic media use: Instead of doing what? Int J Group Tensions. 2000; 29:163-90.

38. Roberts DF, Foehr UG. Trends in media use. Future of Children. 2008; 18:11-37. [PubMed: 21338004] 

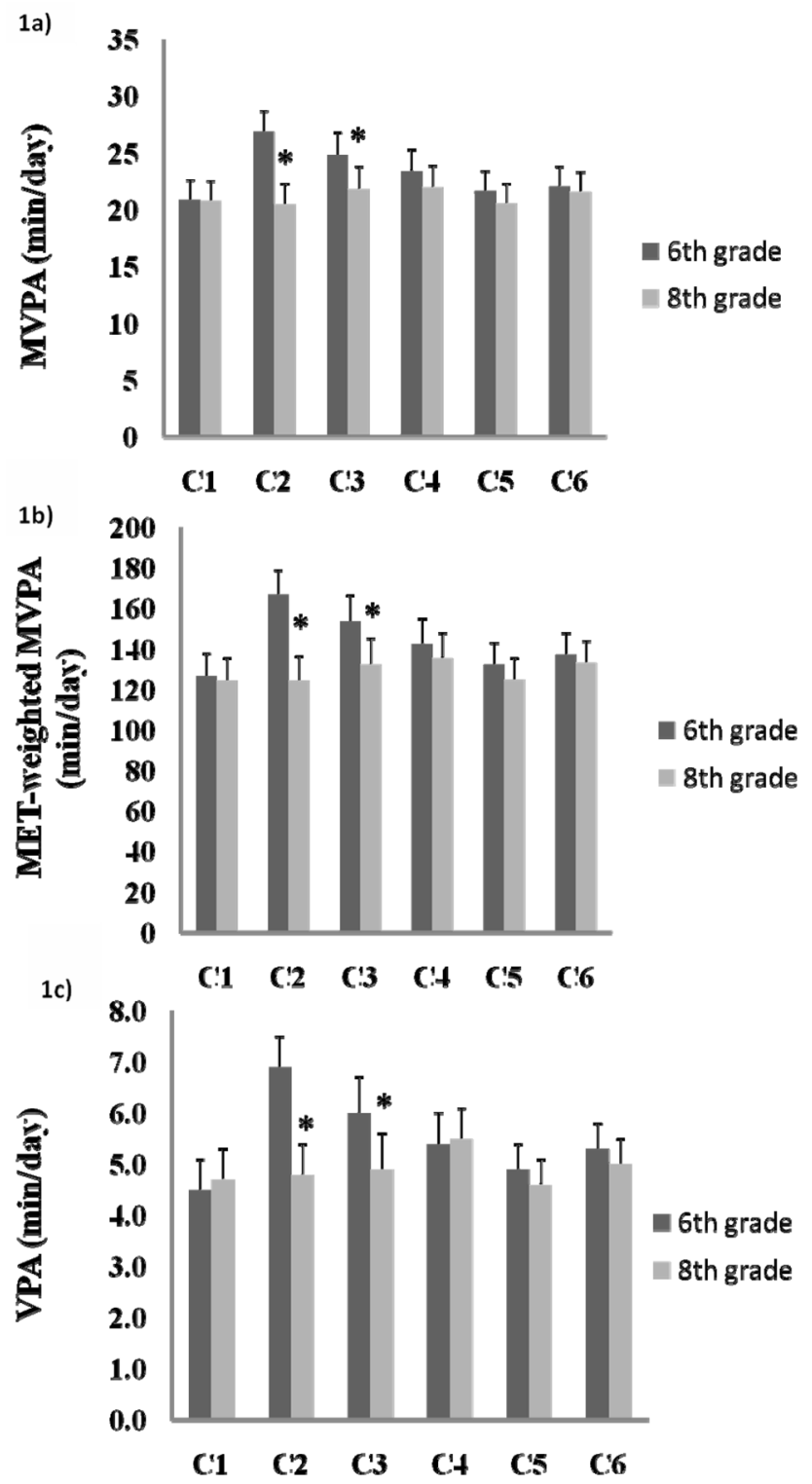

Figure 1.

Physical activity levels by cluster by time: *p $<0.05$ 


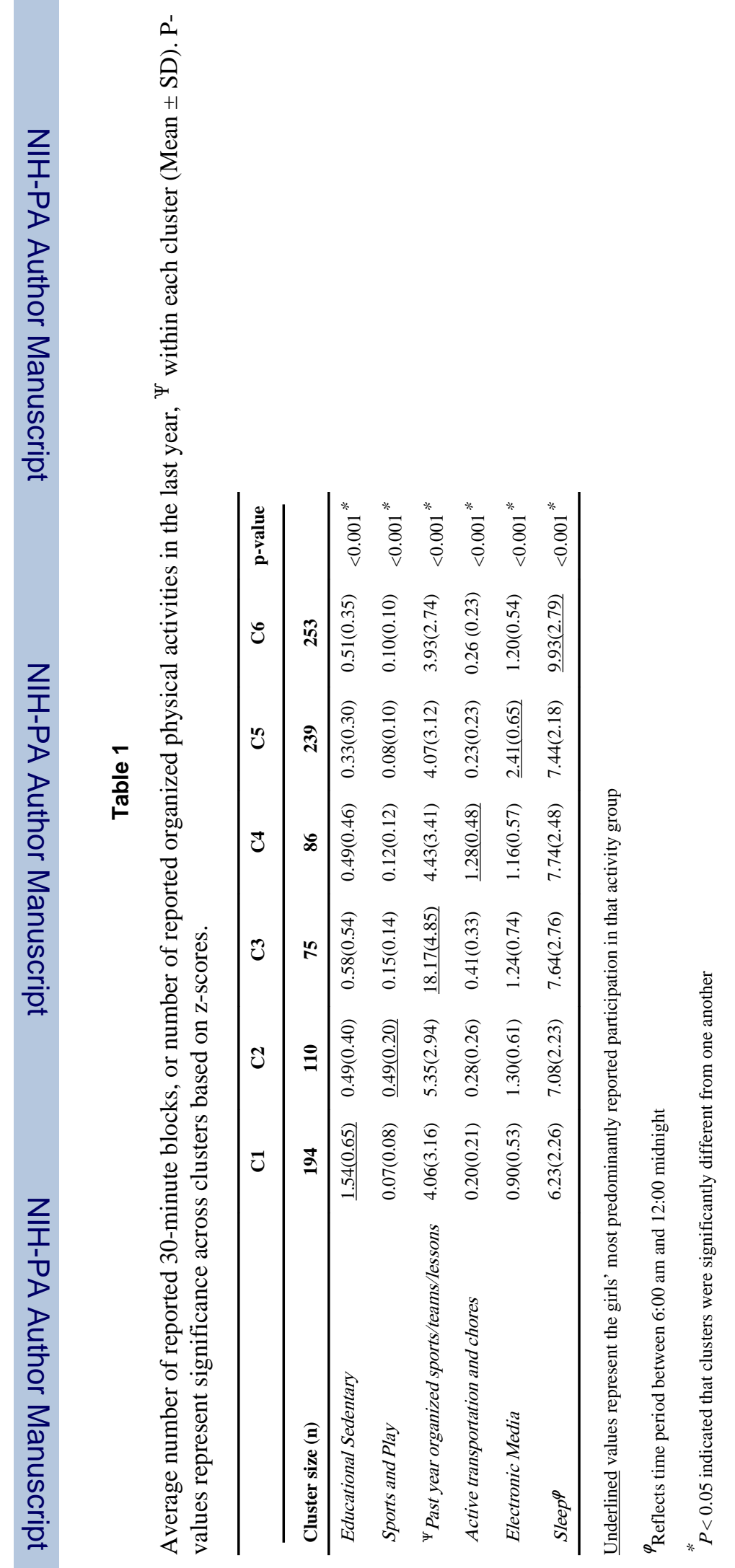




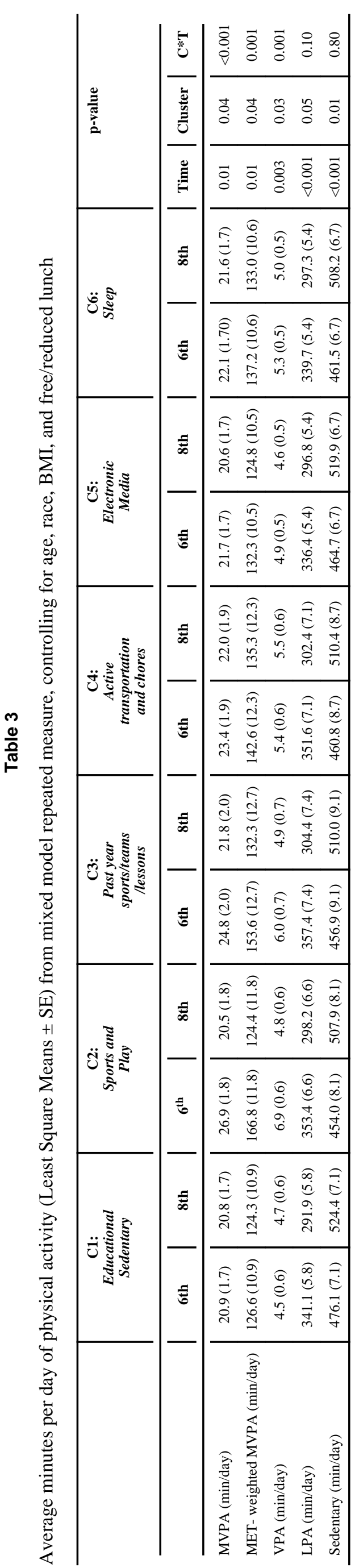

